\title{
Experimental investigation of the coolant flow in the VVER reactor core with TVSA fuel assemblies*
}

\author{
Sergey M. Dmitriyev ${ }^{1}$, Anton V. Gerasimov ${ }^{1}$, Aleksander A. Dobrov ${ }^{1}$, Denis V. Doronkov ${ }^{1}$, \\ Aleksey N. Pronin ${ }^{1}$, Anton V. Ryazanov ${ }^{1}$, Dmitry N. Solntsev ${ }^{1}$, Aleksander Ye. Khrobostov ${ }^{1}$, \\ Aleksey S. Noskov ${ }^{2}$, Oleg B. Samoylov ${ }^{2}$, Yury K. Shvetsov ${ }^{2}$, Dmitry L. Shipov ${ }^{2}$ \\ 1 Nizhny Novgorod State Technical University n.a. R. Ye. Alekseyev, 24 Minina St., Nizhny Novgorod, 603950, Russia \\ 2 JSC Afrikantov OKB Mechanical Engineering, 15 Burnakovskiy proyezd, Nizhny Novgorod, 603074, Russia \\ Corresponding author: Denis V. Doronkov (nevid000@mail.ru)
}

Academic editor: Yury Kazansky • Received 6 June 2019 • Accepted 28 October 2020 • Published 30 March 2021

Citation: Dmitriyev SM, Gerasimov AV, Dobrov AA, Doronkov DV, Pronin AN, Ryazanov AV, Solntsev DN, Khrobostov AYe, Noskov AS, Samoylov OB, Shvetsov YuK, Shipov DL (2021) Experimental investigation of the coolant flow in the VVER reactor core with TVSA fuel assemblies. Nuclear Energy and Technology 7(1): 49-54. https://doi.org/10.3897/nucet.7.65313

\begin{abstract}
The paper presents the results of an experimental study to investigate the coolant interaction in adjoining fuel assemblies in the VVER reactor core composed of TVSA-T and upgraded TVSA FAs. The processes of the in-core coolant flow were simulated in a test wind tunnel. The experiments were conducted using models representing different portions of the VVER reactor core fuel bundle and consisted in measuring the radial and axial airflow velocities in representative areas within the FAs and in the interassembly space. The results of the experiments can be translated to the full-scale conditions of the coolant flow with the use of the fluid dynamics simulation theory. The measurements were performed using a five-channel pressure-tube probe. The coolant flow pattern in different portions of the fuel bundle is represented by distribution diagrams and distribution maps for the radial and axial velocity vector components in the representative areas of the models. An analysis for the spatial distribution of the radial and axial velocity vector components has made it possible to obtain a detailed pattern of the coolant flow about the FA spacer, mixing and combined spacer grids of different designs. The accumulated database for the coolant flow in FAs of different designs forms the basis for the engineering justification of the VVER reactor core reliability and serviceability. The investigation results for the coolant interaction in adjoining TVSA FAs of different designs have been adopted for the practical use at JSC Afrikantov OKBM to estimate the heat-engineering reliability of the VVER reactor cores and have been included in the database for verification of computational fluid dynamics (CFD) codes and detailed by-channel calculation codes.
\end{abstract}

\section{Keywords}

Reactor core, fuel assembly, spacer grids, mixing grids, interassembly interaction, coolant fluid dynamics

\section{Introduction}

Currently, the VVER reactor core at unit 2 of the Temelin NPP has been partially refueled (Dmitriyev et al. 2013b) with fuel assemblies of a new modification loaded as the replacement of the standard TVSA-T FAs. Both fuel assembly designs were developed by JSC Afrikantov OKBM. 
a)
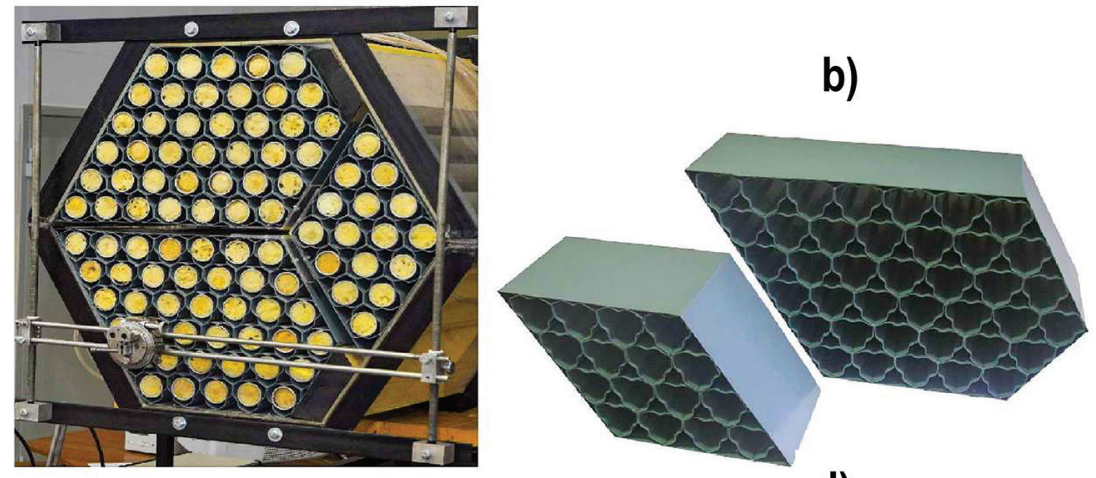

d)

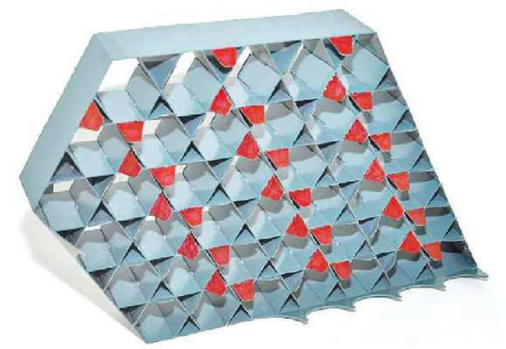

c)

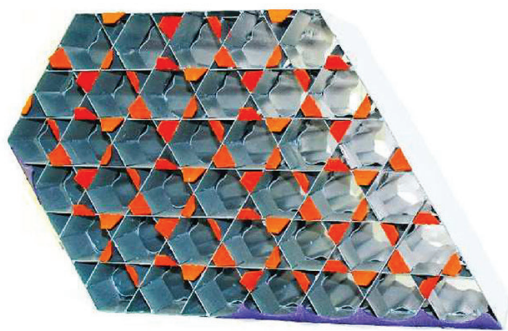

Figure 1. TMs and fuel assembly grid belts: a) VVER core portion TM; b) TVSA ${ }^{\mathrm{U}}$ and TVSA-T SG belt; c) TVSA-T CSG belt; d) TVSA $^{\mathrm{U}}$ MG belt.

As compared with the TVSA-T fuel assemblies, the key distinction of the upgraded TVSA assembly TVSA $^{\mathrm{U}}$ hereinafter) is the use of separately installed mixing grids (MG) which ensure that the coolant mixes more intensively across the assembly, leading so to an improved performance of the new FA (Borodin et al. 2006, Samoylov et al. 2004, 2005, 2010, 2014, Dmitriyev et al. 2012a, b, 2013a, 2014b, 2017).

Both FA types do not have jackets, so the coolant mixing takes place not only in the fuel assembly but also between the adjoining FAs. One needs to take into account this phenomenon when justifying the heat-engineering reliability of the core (Barinov et al. 2016), this calling for integrated studies to be undertaken into the process of the coolant mixing between the adjoining TVSAs of different designs in the mixed VVER reactor core.

\section{Test facility}

The coolant flow in the core was modeled using a wind tunnel test facility (Gerasimov et al. 2020, Samoylov et al. 2019, Dmitriyev et al. 2014a, 2016, 2018, Varentsov et al. 2012, 2015).

Test models (TM) were built reproducing geometrically the structure in different axial areas of the VVER reactor core fuel bundle. All TM components have been proportionally increased by the geometrical similarity coefficient $K_{\mathrm{g}}=4.4$.

The test models included one segment of the TVSA-T assembly, two segments of an upgraded TVSA assembly, and the space between the assemblies (Fig. 1a).
The spacer grid (SG) (Fig. 1b) consists of triangularly packed spring elements joined using a steel rim. The TVSA-T combined spacer grid (CSG) (Fig. 1c) is fitted with vortex generators arranged so that there is a flow swirl around the fuel rod, the offset angle of the vortex generators being $38^{\circ}$. The mixing grid (MG) (Fig. 1d) is fitted with vortex generators with an offset angle of $30^{\circ}$ installed so that the flow is along the fuel rod rows. All grids are fitted with shaped rim offset simulators.

\section{Measuring system}

A pressure-tube probe was used to measure the local hydrodynamic characteristics of the coolant flow. The sensor is designed as five steel capillary tubes installed in two mutually perpendicular planes. The resultant flow pressure field, as shown by the dependencies obtained from calibration tests, was converted to the flow direction and absolute velocity (Dmitriyev et al. 2015). The probe is designed such that not to perturb the flow and not to distort its direction. The error of determining the velocity vector components does not exceed 7\%. The sensor readings were taken using a SAPHIR-22R pressure transducer with the allowable base error limit of $\pm 0.25 \%$.

\section{Investigation procedures}

A representative area, consisting of a standard TVSA-T assembly and two TVSA $^{\mathrm{U}}$ assemblies, was identified in the mixed core's cross-section. Longitudinally, the core 


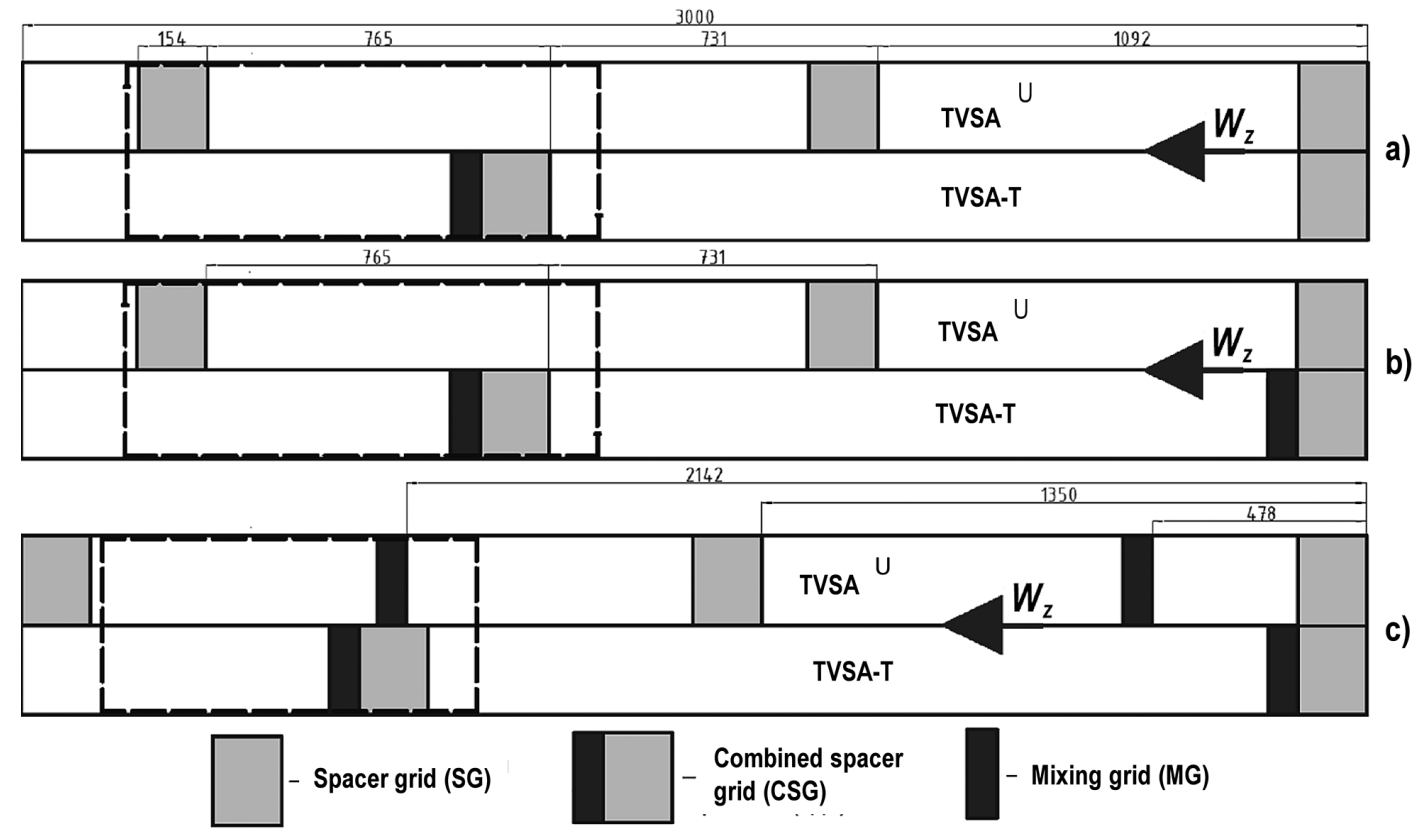

Figure 2. Grid arrangement in different portions of the TVSA fuel bundle: a) "lower" portion; b) "medium” portion; c) “upper" portion.

fuel bundle was divided into three typical axial portions referred to, in accordance with the upward coolant flow direction, as "lower", "medium" and "upper".

The "lower" portion of the fuel bundle starts from the first identically arranged SGs of the fuel assemblies of both types (Fig. 2a). The "medium" portion of the fuel bundle starts from the first identically arranged CSGs and SGs of the standard TVSA-T and the TVSA ${ }^{\mathrm{U}}$ (Fig. 2b). The "upper" portion starts from the first separately installed SG in the TVSA ${ }^{\mathrm{U}}$ (Fig. 2c).

Specific to the TM of the fuel bundle's "lower" portion is that the flow movement inlet conditions are symmetrical, that is, there are spacer grids of the same design installed at the TM inlet for both TVSAs (see Fig. 2a). The TM of the fuel bundle's "medium" portion is distinct in that the flow movement inlet conditions are asymmetrical, that is, a spacer grid and a combined spacer grid are installed at the TM inlet, each for the respective fuel assembly (Fig. 2b). Specific to the TM of the fuel bundle's "upper" portion, apart from the spacer grid and the combined spacer grid installed at the TM inlet, is that there are separately installed mixing grids (see Fig. 2c).

The test procedure was as follows.

1. Representative TM cross-section areas, found in the gap between two adjoining TVSAs and in the gaps between fuel rods in each of the fuel assemblies, were selected to investigate the interassembly coolant mixing process (Fig. 3).

2. The representative TM cross-section areas were broken down into a particular number of measuring zones each of which had the flow pressure fields measured in representative sections along the TM using a pressure-tube probe. The airflow pressure field measuring regions across the TM are shown by a dotted line (see Fig. 2). The resultant distribution of pressures was then converted in the velocity projection on the coordinate axes $x, y, z$, and averaged over the gaps between the fuel rods and the interassembly space (see Fig. 3).

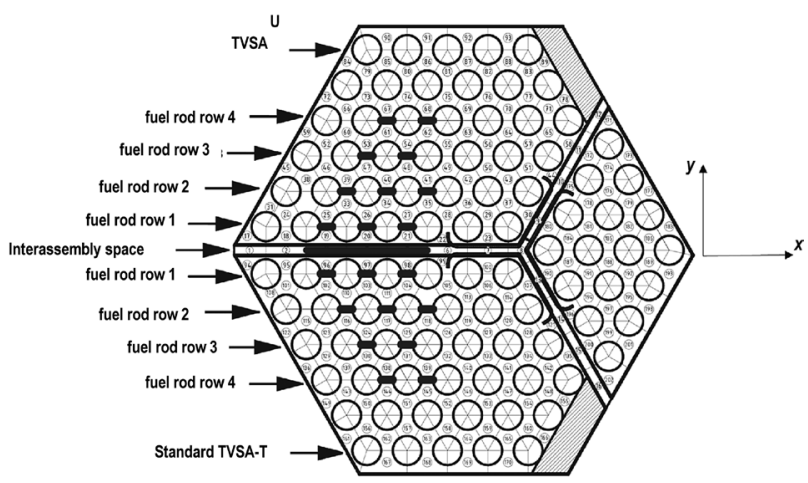

Figure 3. Arrangement of representative gaps in the TM cross-section.

3. The obtained data was used to plot distribution diagrams of the velocity vector components and distribution maps of the TM cross-section axial velocity.

4. The rationale for the representative status of the test facility experimental investigation into the coolant flow current upstream of the intensifier grids was provided in (Samoylov et al. 2004, 2014, Dmitriyev et al. 2012b).

The experimental study was conducted at a constant average rate velocity of the airflow at the TM inlet; this parameters has an equal value for each of the models and amounts to $W_{\text {av }}=27.5 \mathrm{~m} / \mathrm{s}$. The Reynolds number, with which the experiments were undertaken, was equal to 78000. The temperature range of the airflow during the investigation was 23 to $25^{\circ} \mathrm{C}$. 


\section{Results of the interassembly coolant mixing investigations}

An analysis of the experimental investigation results has made it possible to identify general flow current regularities.

1. The transverse coolant flows in all fuel bundles portions are of a similar nature and show the following distribution of the transverse flows: when flowing around the CSG installed in the TVSA-T, the transverse flow moves into the $\mathrm{TVSA}^{\mathrm{U}}$, and upstream of the SG and the MG installed in the $\mathrm{TVSA}^{\mathrm{U}}$ the transverse flow is directed into the TVSA-T. The so formed flows have a major impact on the coolant movement in the neighboring fuel assemblies.

2. The following was observed in the interassembly space:

a) the transverse velocity values for the flow around the CSG and the SG are close and make $\left(W_{y} / W_{\text {av }}\right)$ $=0.3$ in the fuel bundle's "medium" portion and $\left(W_{y} / W_{\text {av }}\right)=0.25$ in the "lower" portion (Fig. 4); in the "upper" portion of the fuel bundle the transverse velocity values for the flow around the CSG and the SG are close and make $\left(W_{y} / W_{\text {av }}\right)=$ 0.2 , this being somewhat less than in the other test portions (see Fig. 4);

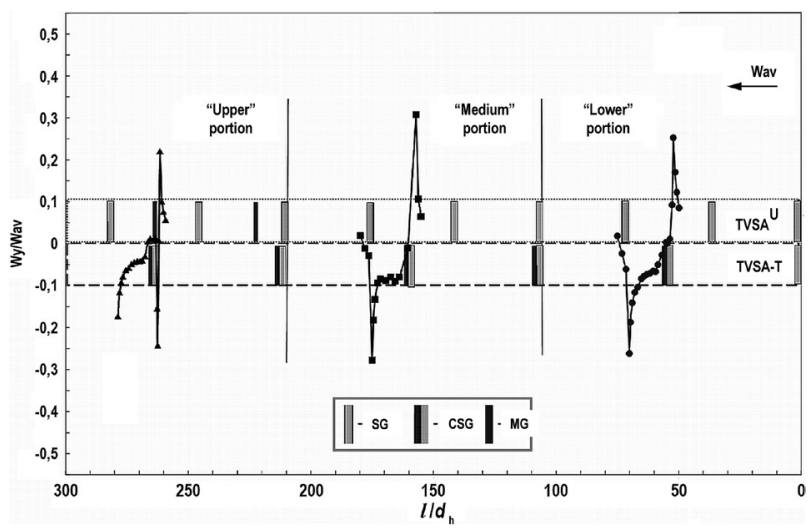

Figure 4. Distribution of the transverse velocity in the interassembly space $\left(W_{\mathrm{av}}=27.5 \mathrm{~m} / \mathrm{s}, \operatorname{Re}=78000\right)$.

b) upstream of the MG installed in the fuel bundle's "upper" portion, the transverse flow moves into the TVSA-T, the velocity value being $\left(W_{v} / W_{\mathrm{av}}\right)=$ 0.25 . This phenomenon is typical only of the interassembly space and is not observed in the fuel bundle (Fig. 6).

3. The following is observed in the first fuel rod row in each of the fuel assemblies adjoining the interassembly space:

a) for the flow around the CSG and the SG in the fuel bundle's "lower" portion, the transverse velocity values are equal and make $\left(W_{y} / W_{\text {av }}\right)=0.4$ (see Fig. 5);

b) the greatest transverse velocity value is observed for the flow around the CSG in the fuel bundle's

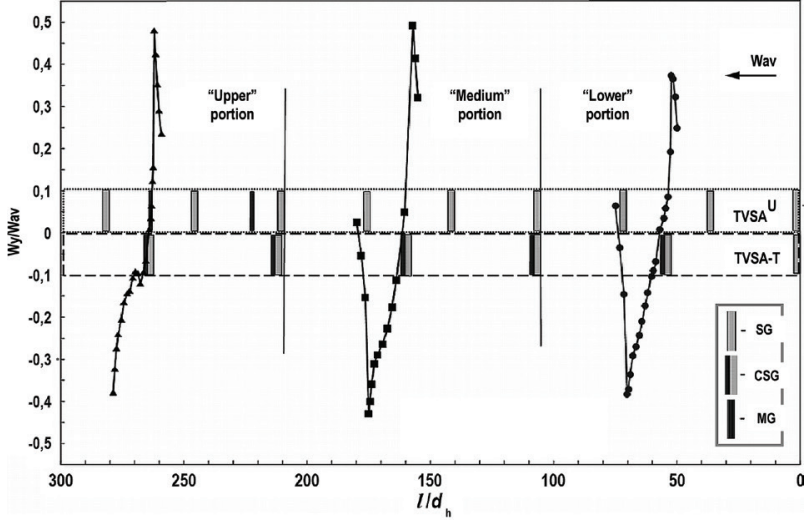

Figure 5. Distribution of the transverse velocity in the first rows of the TVSA fuel elements $\left(W_{\mathrm{av}}=27.5 \mathrm{~m} / \mathrm{s}, \mathrm{Re}=78000\right)$.

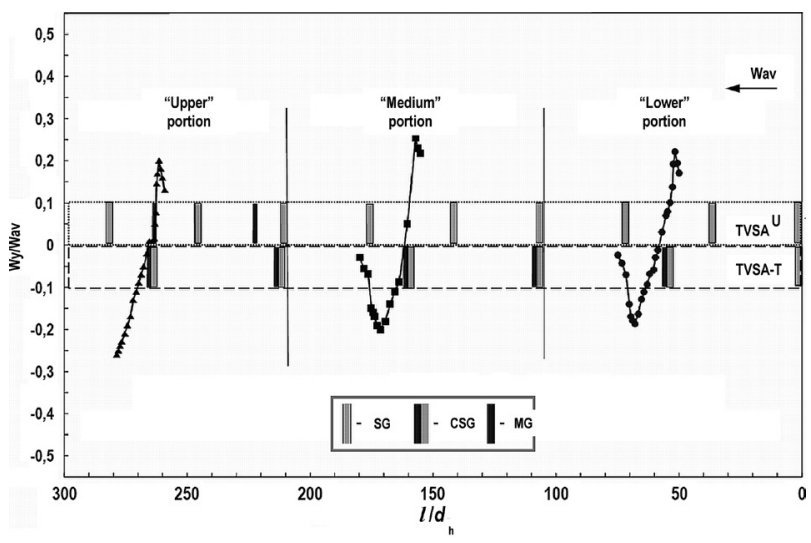

Figure 6. Distribution of the transverse velocity in the second rows of the TVSA fuel elements $\left(W_{\mathrm{av}}=27.5 \mathrm{~m} / \mathrm{s}, \mathrm{Re}=78000\right)$.

"medium" portion, the transverse velocity value being $\left(W_{y} / W_{\mathrm{av}}\right)=0.5$, and for the flow around the SG the transverse velocity has a close value of $\left(W_{y} / W_{\text {av }}\right)=0.45$ (see Fig. 5);

c) for the flow around the CSG in the fuel bundle's "upper" portion the transverse velocity value is $\left(W_{y} / W_{\text {av }}\right)=0.47$, and the transverse velocity for the flow around the SG has a value of $\left(W_{y} / W_{\text {av }}\right)=$ 0.4 (see Fig. 5);

d) for the coolant moving through the fuel bundle's "lower" and "medium" portions the transverse velocity value grows, namely, the transverse velocity values $\left(W_{y} / W_{\mathrm{av}}\right)$ for the flow around the CSG and the SG in the "medium" portion are respectively $20 \%$ and $10 \%$ as high as for the flow around the grids in the "lower" portion (see Fig. 5). The transverse velocity value in the fuel bundle's "upper" portion $\left(W_{v} / W_{\mathrm{av}}\right)$ is close to the velocity values in the "medium" portion.

4. An analysis of the coolant tangential velocity distribution across the fuel assemblies has shown the following:

a) the regularities of the transverse coolant flow distribution along the tested fuel bundle portions, which are typical of the fuel rod row adjoining the interassembly space, apply to the rod 
rows in each of the TVSAs that come next; the distribution of the coolant flow tangential velocities across the TM is limited to the $3^{\text {rd }}$ or $4^{\text {th }}$ row in each of the assemblies, depending on the portion tested;

b) beginning with the second fuel rod row, the transverse velocity value $\left(W_{y} / W_{\text {av }}\right)$ for the flow around the grids of different designs decreases by a factor of two for all of the tested portions (see Figs 5 and 6 );

c) in the "medium" portion of the fuel bundle the distribution depth of the transverse coolant flows across the adjoining fuel assemblies is equal and is limited to four fuel rod rows, the coolant turbulent movement being observed beginning with row 5 , and the transverse velocity being $\left(W_{y} / W_{\text {av }}\right)$ $\approx(0.1-0.05)$;

d) in the fuel bundle's "lower" and "upper" portions the distribution of the transverse coolant flows across the TVSA is limited to three fuel rod rows, the coolant turbulent movement being observed beginning with row 4 , and the transverse velocity being equal to $\left(W_{y} / W_{\text {av }}\right) \approx(0.1-0.05)$.

5. The maximum value of the axial flow velocity in the test portions of the fuel bundle is shown in the region of the three fuel rod rows, which are near the interassembly space at the time the CSG and SG belts are flown around, and is equal to $\left(W_{z} / W_{\text {av }}\right)$ $\approx 1.45$.

6. Due to the CSG and the SG differing hydraulically, the coolant flow rate distribution between the neighboring fuel assemblies becomes highly heterogeneous. The maximum difference in the coolant flow rate between the neighboring assemblies is $38 \%$ being observed in the fuel bundle's medium portion and caused by the greatest transverse flow intensity in this fuel bundle portion.

\section{References}

- Barinov AA, Dmitriyev SM, Khrobostov AYe, Samoylov OB (2016) Concerning the issue of the methodology to justify the heat-engineering reliability of the water-cooled water-moderated power reactor cores. Atomnaya energiya 120(5): 270-275. https://doi.org/10.1007/ s10512-016-0140-9 [in Russian]

- Borodin SS, Dmitriyev SM, Legchanov MA, Khrobostov AYe, Samoylov OB, Sorokin NM (2006) Peculiarities of the coolant hydrodynamics in alternative fuel assemblies of VVER-1000 reactors using mixing grids. Izvestiya vysshykh uchebnykh zavedeniy. Yadernaya energetika 4: 70-76. [in Russian]

- Dmitriyev SM, Borodin SS, Legchanov MA, Solntsev DN, Sorokin VD, Khrobostov AYe (2012a) Experimental studies into hydrodynamic and mass transfer characteristics of the coolant flow in the VVER reactor fuel assemblies. Atomnaya energiya 113(5): 252-257. https://doi.org/10.1007/s10512-013-9638-6 [in Russian]
7. The coolant flow balance between the neighboring fuel assemblies is observed immediately downstream of the SG. The coolant flow rate difference between the assemblies is not more than $10 \%$.

\section{Conclusion}

An analysis of investigation results for the VVER core coolant mixing process has led to the following conclusions:

a) the coolant movement in the fuel bundle in a core composed of TVSA assemblies of different designs is affected by the transverse flows formed as hydraulically different grids are flown around;

b) in the interassembly space, the transverse velocity value for the combined spacer grid and the spacer grid flown around in the fuel bundle's "lower" and "medium" portions in the respective fuel assemblies is the same for both;

c) the maximum transverse velocity value is observed when the combined spacer grid is flown around in the fuel bundle's "medium" portion;

d) the distribution depth of the transverse coolant flows across the fuel assemblies is limited to four fuel rod rows in the fuel bundle's "medium" portion and to three fuel rod rows in the fuel bundle's "lower" and "upper" portions;

e) when the coolant moves through the fuel bundle's "lower" and "medium" portions, there is a growth observed in the flow's transverse velocity value, and there is no transverse velocity growth in the "upper" portion;

f) the coolant flow balance between the neighboring fuel assemblies in the fuel bundle's "medium" and "lower" portions is observed immediately downstream of the spacer grid.
- Dmitriyev SM, Lukyanov VYe, Samoylov OB (2012b) Justification of the correlation for calculating the critical heat flux in fuel assemblies of an alternative design with stirring intensifier grids for the VVER-1000 reactor. Izvestiya vysshykh uchebnykh zavedeniy. Yadernaya energetika 1: 99-108. [in Russian]

- Dmitriyev SM, Varentsov AV, Dobrov AA, Doronkov DV, Legchanov MA, Khrobostov AYe (2013a) Investigation of the coolant mass transfer downstream of the mixing grids in the fuel assemblies of the VBER-300 reactors for justifying their efficiency. Trudy NGTU im. R.Ye. Alekseyeva 5: 197-205. [in Russian]

- Dmitriyev SM, Zverev DL, Bykh OA, Panov YuK, Sorokin NM, Farafonov VA (2013b) Key Equipment of Nuclear Power Plants with Thermal Neutron Reactors. Moscow. Mashinostroyeniye Publ., 415 pp. [in Russian]

- Dmitriyev SM, Doronkov DV, Pronin AN, Solntsev DN, Sorokin VD, Khrobostov AYe (2014a) Computational and experimental stud- 
ies into the coolant hydrodynamics and mass transfer downstream of the fuel assembly spacer grid for the floating power unit reactor Izvestiya vysshykh uchebnykh zavedeniy. Yadernaya energetika 4: 60-70. https://doi.org/10.26583/npe.2014.4.07 [in Russian]

- Dmitriyev SM, Varentsov AV, Dobrov AA, Doronkov DV, Samoylov OB, Sorokin VD, Khrobostov AYe (2014b) Computational and experimental studies into the local hydrodynamics and mass exchange of the coolant flow in TVS-Kvadrat assemblies with mixing grids for the PWR reactors. Teploenergetika 8: 20-27. [in Russian]

- Dmitriyev SM, Dobrov AA, Legchanov MA, Khrobostov AYe (2015) Application of a multichannel pressure-tube probe to study the coolant velocity profile in models of the nuclear reactor fuel assemblies. Pribory i metody izmereniy 6(2): 188-195. [in Russian]

- Dmitriyev SM, Doronkov DV, Legchanov MA, Pronin AN, Solntsev DN, Sorokin VD, Khrobostov AYe (2016) Investigation of the coolant flow hydrodynamic characteristics and features downstream of the fuel assembly spacer grids for the floating power unit reactor. Teplofizika i aeromekhanika 23(3): 385-394. https://doi. org/10.1134/S0869864316030069 [in Russian]

- Dmitriyev SM, Varentsov AV, Doronkov DV, Pronin AN, Solntsev DN, Khrobostov AYe, Sukharev YuP (2017) Experimental studies into the hydrodynamics of the coolant flow downstream of the TVSA-12PLUS spacer and mixing grids for the VVER-1000 reactor VANT. Ser. Fizika yadernykh reaktorov 1: 126-134. [in Russian]

- Dmitriyev SM, Dobrov AA, Doronkov DV, Pronin AN, Solntsev DN, Sorokin VD, Khrobostov AYe (2018) Studies into the coolant flow hydrodynamic processes in the TVS-Kvadrat fuel assemblies with different mixing grids for the PWR reactors. Teplofizika i aeromekhanika 25(5): 725-734. https://doi.org/10.1134/ S0869864318050062 [in Russian]

- Gerasimov AV, Dmitriyev SM, Dobrov AA, Doronkov DV, Pronin AN, Ryazanov AV, Solntsev DN, Khrobostov AYe (2020) Computational and experimental studies into the processes of the coolant flow in the region of the guide channel upstream of the fuel assembly mixing grids. Inzhenerno-fizicheskiy zhurnal 93(1): 151-160 https://doi.org/10.1007/s10891-020-02102-x [in Russian]
- Samoylov OB, Shipov DL, Falkov AA, Bogryakov VG, Sorokin NM, Dmitriyev SM (2004) Thermal-hydraulic and hydrodynamic studies of the characteristics of TVS assemblies of an alternative design for the VVER-1000 reactor. VANT. Ser. Fizika yadernykh reaktorov 2: 47-55. [in Russian]

- Samoylov OB, Kuul VS, Preobrazhenskiy DG (2005) Results of developing and evolving fuel assemblies of an alternative design for the VVER-1000 reactor. VANT. Ser. Materialovedeniye i novye materialy 1: 126. [in Russian]

- Samoylov OB, Falkov AA, Morozkin ON, Lukyanov VYe (2010) Refinement of the methodology for taking into account deviations of local parameters when justifying the heat-engineering reliability of a core composed of the VVER-1000 reactor's TVSA assemblies. Trudy NGTU im. R.Ye. Alekseyeva 4: 111-119. [in Russian]

- Samoylov OB, Kupriyanov AV, Falkov AA, Shipov DL, Molodtsov AA, Lukyanov VYe (2014) Experimental studies of the heat-engineering characteristics of TVSA assemblies with mixing grids. Atomnaya energiya 116(1): 11-14. https://doi.org/10.1007/s10512014-9810-7 [in Russian]

- Samoylov OB, Noskov AS, Shipov DL, Dmitriyev SM, Dobrov AA, Doronkov DV, Legchanov MA, Pronin AN, Solntsev DN, Sorokin VD, Khrobostov AYe (2019) Hydrodynamic features of the coolant flow downstream of the TVS-Kvadrat mixing spacer grid for the PWR reactor. Teploenergetika 4: 32-38. https://oi.org/10.1134/ S0040601519040074 [in Russian]

- Varentsov AV, Doronkov DV, Kupricheva YeS, Solntsev DN, Sorokin VD (2012) Experimental studies into the local mass transfer and the efficiency of coolant mixing in the fuel assemblies of the KLT-40S reactor using spacer grids. Trudy NGTU im. R.Ye. Alekseyeva 1: 107-113. [in Russian]

- Varentsov AV, Doronkov DV, Ilyutina YeM, Karatushina IV, Sorokin VD, Khrobostov AYe (2015) Peculiarities of the coolant flow in the TVS-Kvadrat assembly of the PWR reactor with installed spacer mixing grids using different types of deflectors. Trudy NGTU im. R.Ye. Alekseyeva 3: 134-143. [in Russian] 